\title{
Liberalismo y conservadurismo en la formación disciplinaria de la Administración Pública
}

\author{
Jaime EsPejel MenA \\ Universidad Autónoma del Estado de México \\ jaimeespejel@hotmail.com
}

Recibido: 09/10/2015

Aceptado: 27/11/2015

\begin{abstract}
Resumen
El propósito del presente documento es revisar, de manera resumida, el liberalismo y conservadurismo como ideologías que se expresaron en proyectos de la modernidad ulteriores a la Revolución Francesa, para comprender su influencia en la conformación histórica y en la concepción epistemológica de la administración pública, como ciencia social heredada de la Ilustración. Se concluye planteando que ha predominado un pensamiento liberal progresista en la forma de argumentar el quehacer disciplinario de las ciencias administrativas.
\end{abstract}

Palabras clave: liberalismo, conservadurismo, revolución, administración pública, Ilustración, modernidad.

\section{Liberalism and conservatism in the disciplinary formation of the public administration}

\begin{abstract}
The purpose of this document is to review, in summary, as liberalism and conservatism ideologies were expressed in subsequent projects modernity of the French Revolution, to understand their influence in shaping the historical and epistemological conception of public administration, as social science inherited from the Enlightenment. We conclude proposing that has prevailed a progressive liberal thinking in how to argue the disciplinary work of administrative sciences.
\end{abstract}

Key words: liberalism, conservatism, revolution, public administration, illustration, modernity.

\section{Introducción}

El proyecto de modernidad es la consecuencia de las continuidades y rupturas de los complejos procesos de formación y consolidación de conocimientos, métodos y técnicas; de la confirmación de medios de acción, de las clases sociales, de la acumulación de riqueza; de la irrupción de instituciones, ideologías y doctrinas, y de la ratificación de procesos más o menos globales, en un extenso y complejo espacio de tiempo. La modernidad es la consecuencia del nacimiento, traslape y convivencia, a ritmos desiguales, de procesos de carácter político, económico, social y cultural que se confirman en un proyecto de Estado y de sociedad. 
La historia del pensamiento de los proyectos de modernidad, se suele ordenar de dos maneras: 1) la reflexión sobre los descubrimientos que proceden únicamente de los individuos y 2) el estudio de los sistemas, escuelas, movimientos o doctrinas. El presente documento considera que el liberalismo y el conservadurismo son dos ideologías por sus consideraciones razonablemente coherentes, por sus ideas morales, políticas, económicas, sociales y culturales, la otra es el socialismo. Estas ideologías han sobrevivido por un tiempo considerable, con sus defensores y retractares, con amplios o limitados márgenes de institucionalización. Las ideologías son poco observables, requieren prácticas o acciones políticas para ser observadas, son evocadas por los partidos políticos, en las leyes aprobadas, en manifiestos y acciones de los gobernantes y hasta en los proyectos de Estado. Sostenemos que los pensamientos y los hechos no se forman o presentan de manera atomizada, se presentan en pautas, en sistemas o en estructuras de pensamiento, es decir, las doctrinas y valoraciones se hacen presentes en todo sistema de pensamiento.

El presente documento resume en forma de esbozo sintético, la revisión epistemológica e histórica de algunas ideas representativas de la modernidad y el estudio de sus concepciones de la administración pública, se emprende tomando como punto de referencia empírico el desarrollo de éstas después de la Revolución Francesa (1789-1799). En la época de Jean-Jacques Rousseau (1712-1778), se presencia una paz inquietada por la Revolución Francesa y el golpe de Estado de Napoleón Bonaparte. En 1815 el mundo político francés regreso a la tranquilidad, una serenidad incompatible con toda forma de cambio, sólo los fervientes partidarios del statu quo presenciado por Luis XIV el Rey Sol (1643-1715) y su celebré frase «El Estado soy yo» podían tolerar. Entrado el siglo XIX se celebra el Congreso de Viena y la alianza militar, entre el emperador Alejandro I de Rusia, el emperador Francisco I de Austria y el rey Federico Guillermo III de Prusia, el 26 de septiembre de 1815, mejor conocida como la Santa Alianza -en 1818 se incorporaran Inglaterra y Francia-, la intención es poner la paz en Europa, después de las largas guerras napoleónicas, a través de difundir los valores cristianos: fe, caridad, justicia y paz. En general el propósito es mantener al absolutismo como régimen político dominante en Europa, la Santa Alianza se oponía a las revoluciones democráticas y al laicismo. Dos fueron las respuestas contra el sistema de la Santa Alianza y sus ideales: 1) la rebeldía del industrialismo, la monarquía, la aristocracia, de los filósofos radicales del movimiento librecambista-Sebastián Le Prestre, Señor de Vauban (1633-1707), Pierre Le Pesant, Señor de Boisguilbert (1646-1714), François Quesnay (1694-1774) y Adam Smith (1723-1790)- y hasta del socialismo marxista y 2) la rebelión romántica, los románticos no querían la armonía y la calma, deseaban una vida individual pujante y entusiasta, no profesaban simpatía por el industrialismo, ya que este denigraba el alma con el dinero e interfería la libertad individual. Durante y después del periodo revolucionario el movimiento romántico fue metido en la política por los nacionalistas y conservadores.

En la conformación disciplinaria y epistemológica de la administración pública está la presencia de algún proyecto liberal o conservador de la modernidad. Esta observación evita dar un contenido específico al proyecto de la misma modernidad, presentar un proyecto como el deber ser, como la señal de lo que moral y políticamente debe ser realizado y aceptado por la sociedad. Las capacidades sociales e históricas de nues- 
tra nación permiten o imposibilitan el acto de proyectar y realizar el contenido teórico y práctico de las aspiraciones. Es decir, existe una tensión en el nivel teórico y práctico entre el Estado y la Nación, desde la gestación del Estado moderno y en su sinuoso progreso. Entre derecho natural y espíritu nacional, entre Estado de Derecho y Estadonación, entre Ilustración iusnaturalista e historicismo romántico, entre liberalismo y conservadurismo, en esa pugna teórica y práctica se revalida la paternidad del proyecto de modernidad. Empero, tanto el liberalismo como el conservadurismo son expresiones de la naciente ideología burguesa.

El supuesto del documento sugiere que la naturaleza disciplinaria de la administración pública -en el contexto genético de las ciencias sociales- mantiene una relación estrecha con el referente empírico de la modernidad liberal progresista y a su vez con su concepción mensurable de argumentación y comprobación, aun cuando, el programa o discurso de los gobiernos se acerque al conservadurismo. La forma de enseñar y estudiar a la administración pública está en sintonía con la argumentación liberal progresista de la modernidad - con la racionalidad burguesa y el universalismo de los conceptos utilizados para interpretar una realidad-, la clásica idea del pacto social, del bien común, de la administración pública como el punto que relaciona al Estado con la sociedad, la soberanía, el individualismo, y la utilización de una serie de conceptos y técnicas para una demostración empírica a través del uso de las matemática, son un claro ejemplo. Se presenta un claro alejamiento del anti-racionalismo, del culto a lo inconsciente, de la argumentación lógico-histórica, de lo esotérico, de la fe, de los valores antidemocráticos, de los hábitos, de la costumbre, del prejuicio y en general de las costumbre. Se aparta del supuesto que en la tradición se puede encontrar una norma sistematizada y viable de conocimiento práctico, de conducta individual y de convivencia social y política.

\section{Los orígenes del liberalismo}

Los orígenes del liberalismo están en las ideas optimistas de la Ilustración y en la concepción individualista de la sociedad -de manera genérica se apela a la necesidad de los derechos humanos y no a la utilidad propia de la sociedad y del Estado-, algunos autores que ejemplifican el pensamiento liberal son: John Locke (1632- 1704), Charles Louis de Secondat y Barón de Montesquieu (1689-1755), François Marie Arouet (1694-1778), más conocido como Voltaire y Denis Diderot (1713-1784), por mencionar algunos (Lassalle, 2010).

Los principales iniciadores de la Ilustración se hallan inscritos en el ámbito de la burguesía ascendente, pero sus promotores no fueron ni todas las capas burguesas, ni solamente éstas. Por un lado, tuvo sus adversarios en determinados sectores de la alta burguesía comercial, y por otra parte, en ciertos elementos del bajo clero o de la nobleza cortesana, e incluso el propio aparato estatal del despotismo ilustrado -Federico II, Catalina II y José II-, la apoyaron aunque en este último caso, como simple instrumento de política internacional (Ruggiero, 2005). Empero, el cambio brusco no llego del todo por la Ilustración, en parte porque sólo la minoría acomodada sabía leer y contaba con el tiempo para hacerlo y porque la Ilustración fue más reformista que revolucionaria, anhelaba un siste- 
ma perfecto, organizado científicamente, regulado por la razón y gobernado por tiranos generosos. La Ilustración quiso reunir todos los conocimientos científicos y hacerlos accesibles a todos los círculos sociales. La filosofía en la Ilustración se conformó con los resultados de la ciencia natural y las doctrinas empiristas de los ingleses; es la difusión de la parte menos metafísica del cartesianismo y del pensamiento británico, el Diccionario histórico y crítico de Pierre Bayle (1647-1706) y los 28 volúmenes de la Enciclopedia o diccionario razonado de las ciencias, artes y oficios de Denis Diderot (1713-1784) y Jean Le Rond D'Alembert (1717-1783) son un claro ejemplo (Bonazzi, 2015).

Las condiciones nacidas en Inglaterra a mediados del siglo XVII, entre la guerra civil (1642-1651) y la Revolución Gloriosa de 1688 formularon argumentos contra el poder absoluto de la monarquía representada por Jacobo II de 1685 a1688 y por Guillermo III y María II de 1689 a 1702 y contra el poder de la iglesia y su verdad religiosa, así como la demanda de tolerancia religiosa a la dominación del protestantismo de origen calvinista y el catolicismo romano. Durante el mandato de Oliver Cromwell (1599-1658) se presentó el reconocimiento de distintas sectas protestantes: calvinismo, luteranismo y unitarismo. La demanda de tolerancia religiosa y el reclamo de un concepto de comunidad política fundado en el libre acuerdo de sus integrantes, son los argumentos a los que John Locke (1632-1704) recurrió para desarrollar la idea del primer liberalismo Inglés (Santirso, 2014).

La Revolución (1789-1799) le dio a Francia sus primeros inicios de partidos políticos. Napoleón Bonaparte, de acuerdo con la idea plebiscitaria del cesarismo, no había querido partidos. Para él los franceses debían manifestarse unánimemente en el amor a la patria y a su gobierno. La salvaguardia del liberalismo francés está en el supuesto que los individuos encuentran en su reconocimiento, no en la soberanía popular, sino en la extensión de sus límites y en último término, en las garantías políticas frente al soberano, en el monarca o en el pueblo. La Revolución Francesa (1789-1799) fue la primera revolución liberal burguesa europea, representa el fin del Antiguo Régimen, la abolición de la servidumbre y el sistema feudal. El liberalismo francés buscará desarrollar una apertura del poder del monarca a través de un nacionalismo centrífugo y de la consolidación de la libertad civil. Se consolida la libertad política en una Carta Constitucional, se garantizan a todos los ciudadanos sus derechos y obligaciones. Se crearon dos cámaras a las que se les concedía el derecho a votar los impuestos y a colaborar en la aprobación de leyes. El sufragio se mantuvo como un privilegio para los mayores contribuyentes, el cuerpo electoral era aún limitado (Lomba, 2014).

La división de poderes estuvo acompañada de las garantías para la libertad de prensa, de expresión y pensamiento. Una garantía más contra el despotismo fue la autonomía provincial y municipal. Para los franceses de la revolución el poder municipal juega un papel fundamental en la división tradicional de los poderes públicos. Con todo el liberalismo francés ratifico su tradicionalismo con el contacto de una mentalidad racionalista. Después de una crisis revolucionaria sintieron la necesidad de consolidar las conquistas ya ganadas no de realizar otras nuevas. A finales de 1803 la corriente secundaria o colateral de Juan Bautista Say (1767-1832) influirá en el pensamiento de los economistas franceses. Say difundió las nacientes ideas de la joven ciencia económica, explico el declive de la fisiocracia, las bondades del industrialismo y del antiestatismo (Fernández, 2012). 
Los fundamentos intelectuales del liberalismo inglés tuvieron un desarrollo mayor por los aportes de los filósofos liberales escoceses, entre los que destacan David Hume (1711-1776), Adam Smith (1723-1790) y Adam Ferguson (1723-1816). Las contribuciones sobre el entendimiento humano, la visión de un orden autoregulador que se forma espontáneamente si los individuos son controlados por las normas legales adecuadas y la reflexión sobre la historia de la sociedad civil, son algunos ejemplos. El liberalismo escocés tomo los criterios racionalistas y humanistas de la Ilustración inglesa, francesa y alemana, especialmente los principios franceses fueron preponderantes. La originalidad del liberalismo escocés estriba en la importancia que se da a la razón y la negación de todo tipo de autoridad que no fuera justificada en ella. Existe una percepción optimista de la capacidad del individuo para mejorar la sociedad y la naturaleza sólo empleando su entendimiento humano (Marías, 2008).

El liberalismo alemán ofrece un interés histórico por las apariencias de sus expresiones doctrinales y por el desarrollo de las complejas influencias que han desviado y dificultado su orientación. La Revolución Francesa le ofreció a Alemania la pequeña y media propiedad, la sociedad agrícola ya liberada del feudalismo y una cultura espiritual preparada para el nacimiento del derecho común que constituye la esencia del liberalismo. El lazo ideal que se había conformado durante la Edad Moderna por el Sacro Imperio Romano Germánico, impuso la necesidad para los alemanes de un nuevo vínculo, el liberalismo con su sentimiento de autonomía e independencia despertó una fuerte conciencia nacionalista, la idea de patria, nación alemana, constituyó el nuevo lazo que sustituyo al maltrecho vínculo imperial. Alemania como pueblo que carece de una tradición política unitaria, sólo la libertad les ofreció la idea de una ciudadanía común capaz de sujetar y dominar la desintegración política. Para los alemanes esta ciudadanía era completamente ideal y su nación era una cultura nación. Su libertad radica esencialmente en el pensamiento. No obstante, si esta unidad ideal y literaria compensa los espíritus en el primer momento del romanticismo, la dolorosa experiencia de la época napoleónica pone, en cambio, de manifiesto el escaso beneficio comparado con la potencialidad de su fuerza, y hasta qué punto el fraccionamiento en Estados ejerce una influencia sombría sobre todas las actividades individuales y públicas. La idea de que la nación cultura tiene su realización completa únicamente en la nación política, comienza a abrirse camino en la conciencia alemana, en el transcurso de la generación de Alexander von Humboldt (1767-1859) y Johann Gottlieb Fichte (17621814) se logra convertir el ingenuo patriotismo cosmopolita en un sistema de Estado nacional (Strauss, 2007).

Los ideales de la Revolución Francesa recibieron en un primer momento un feliz recibimiento por los exponentes más importantes de la cultura alemana. En las afirmaciones de Johann Wolfgang von Goethe (1749-1832), Immanuel Kant (1724-1804) y Friedrich Schiller (1759-1805), reconocen los fundamentos históricos más importantes de aquellos mismos ideales alemanes de vida espiritual y autónoma que a su propio conocimiento habían concedido.

Poco más de una decena de años antes a la Revolución Francesa la Guerra de Independencia de los Estados Unidos (1775-1783), concreta el nacimiento de la primer república organizada a partir de una Constitución escrita y de un sistema federal -en Europa existieron repúblicas, aun que de pequeño tamaño: Venecia, las provincias de 
los Países Bajos y Portugal en el siglo XVI y por un tiempo Cataluña-. La novedad progresista residía en ofrecer a sus ciudadanos una soberanía compartida y organizada por un gobierno. La independencia de los Estados Unidos, no era el primer agravio que recibían las monarquías, pero era la primera predicación de que todos los hombres son creados iguales, que todos son dotados por su Creador de ciertos derechos inalienables, como la vida, la libertad y la búsqueda de la felicidad. Estos principios heredados por la voluntad de Dios, serán para el iusnaturalismo la igualdad legal, la seguridad, la libertad y el derecho a la propiedad (Santirso, 2014).

El liberalismo de los Estados Unidos es considerado, desde la época de Alexis de Tocqueville (1805-1859), como liberalismo democrático. La revolución americana tuvo un carácter preponderantemente político, social y económico. No derribó un régimen señorial que nunca había radicado en América del Norte. Ante todo se inhabilitó la anticipación por herencia de la propiedad inmobiliaria, con excepción de Massachusetts, Delaware y Rhode Island. No se puso completo fin a la esclavitud, permaneció como la contradicción más grave del régimen y el principal motivo de conflicto entre los Estados. El liberalismo de los Estados Unidos recupero los valores liberales de los ingleses y franceses, el excepcionalísimo del liberalismo norteamericano se hizo presente desde Benjamin Franklin (1706-1790), John Adams (1735-1826), Thomas Paine (1737-1809), Thomas Jefferson (1743-1826), James Madison (1751-1836), Alexander Hamilton (1755-1804) y John Louis O'Sullivan (1813-1895), entre otros (Hamilton, Madison y Jay, 2001). En la Constitución Política de los Estados Unidos se hace alusión a las piezas claves del liberalismo, todos los seres humanos tienen derechos naturales y el propósito del gobierno es defender esos derechos, la felicidad y la dignidad deberán ser desarrolladas como metas fundamentales por todos los individuos. En El Federalista Hamilton, Madison y Jay desarrollan el diseño de un gobierno republicano y federal. La monarquía y la república se distinguen como lo malvado y lo divino, como el mal y el bien, Dios está del lado de lo divino y del bien, del lado del liberalismo estadounidense, del amor al trabajo honesto y el engrandecimiento de la comunidad a través del trabajo duro (Touchard, 2006).

\section{La modernidad liberal progresista}

El pensamiento liberal no ha caminado por el mismo sendero, el siglo XVIII no es sólo despotismo ilustrado, racionalismo y neoclasicismo. Coexisten con estas tendencias dominantes las corrientes deístas y místicas, que reivindica el valor de los sentimientos y de la pasión. El siglo XVIII es heredero del aprecio de lo irracional, lo sentimental y de la valoración de la sensibilidad humana, con lo que se identificará al siglo XIX. Por un lado, la Ilustración liberal heredo del Renacimiento una reordenación del mundo y un impulso al progreso de las ciencias, todo ello necesario para acabar con la metafísica, los prejuicios, la superstición y exponer la relatividad de las costumbres que se respetaban como verdades reveladas. La Ilustración cumplió su tarea: conceder al hombre el poder de cuantificar, controlar, conquistar la naturaleza y dominarla en un sueño de progreso hacia la felicidad. Pero los pensadores ilustrados imponen límites al conocimiento: ante la imposibilidad de conocer la cosa en sí, sólo se interesan por el 
conocimiento de los fenómenos, de la realidad sensible, considerando que aquello que nuestros sentidos no pueden concebir no tiene ninguna utilidad. La modernidad liberal progresista sustentara su proyecto en las cualidades materiales de los objetos (unidad, variedad, regularidad, orden, proporción) más que de la sensación que producen éstos en quien los contempla (Groethuysen, 1943).

La diversidad de la palabra liberal procede de las ramificaciones presentadas en distintos momentos, pero, éstas se acreditan en un inicio en un tronco común, se levantan sobre la noción de libertad. Las variantes del liberalismo buscan el poder o teorizan sobre él, son revolucionarias o conservadoras, ambas tienen un sentido práctico y una antipatía a las verdades absolutas, poseen una mayor claridad en lo que rechazan que lo que desean. El liberalismo no se marca un objetivo, no es finalista, traza una ruta sin fijar un fin; el carácter finalista del liberalismo a través de un marcado objetivo preciso, explica su declive cuando este llegó. Los liberales tienen dos cosa en común: 1) la aceptación de la estructura fundamental del Estado y la economía y 2) la aprobación que el progreso reincide en la liberación de la mente y el espíritu humano de los lazos religiosos y tradicionales que los unían al viejo orden, el ethos del liberalismo está en la emancipación individual de todo orden establecido (Kofler, 1974).

La formación de lo que más tarde, de manera genérica, se llamaría «liberalismo» se produjo al mismo tiempo que los cambios sociales y económicos que alumbraron nuestra civilización actual, si las alteraciones materiales y mentales se retroalimentaron, habrá que remontarse hasta una primera ruptura clara del viejo orden señorial para encontrar el origen del nuevo ideario. La libertad es sólo un aspecto en la vida del hombre, el liberal valora la mente, su existencia, autonomía y no se sujeta a autoridad alguna, salvo que la autoridad sea legitima y aminorada por algún esquema de representación, como bien podría ser una república. En un sentido moderno el liberalismo privilegia la libertad sobre la autoridad, la soberanía y las leyes emana exclusivamente del pueblo, no hay una norma fija e inmutable, las leyes son las respuestas a las necesidades y las necesidades cambian en un proceso histórico de progreso. Este punto los europeos continentales lo localizan en la revolución francesa (Ruggiero, 2005). El progresista se mueve en su visión del futuro y lucha por el cambio. El liberalismo europeo demuestra diferentes mentalidades nacionales, se creó una particular conciencia liberal (véase Tabla 1). En las dos formas típicas del liberalismo, la inglesa y la francesa, encontramos argumentos inconciliables durante el siglo XVIII. No obstante, el proceso inglés orientado a la democratización y racionalización, mientras que el proceso francés inclinado a una orientación histórica y a particularizar su contenido racional durante el transcurso del siglo XIX los llevó a disminuir sus diferencias. La primera causa que planteó la necesidad de pacificación del conflicto es la antítesis que se presenta entre la libertad en singular y las libertades en plural. Dos sistemas políticos representaron esta fórmula. Uno hace de las libertades un conjunto de franquicias y de dispensas particulares, conquistadas una a una, con autonomía de toda formula conceptual que las unifique y las relacionen unas con otras (Laski, 1974). El otro hace de la libertad un ente de razón, un concepto que quiere llegar a la esencia de la personalidad humana por encima de toda contingencia histórica y empírica. Para los franceses de la época revolucionaria, las libertades de las que los ingleses estaban orgullosos, no 
eran más que privilegios de una minoría, con daño para toda la comunidad, el complemento era una esclavitud que contradecía la verdadera libertad que constituye la esencia misma de la personalidad humana. Para los ingleses, la Declaración de los Derechos del Hombre y del Ciudadano en 1789 es un principio abstracto y carente de toda garantía y de toda sanción práctica, destruye privilegios irracionales e injustos, todas las garantías y las sanciones que la historia ha creado. Hace a los individuos un agregado de átomos similares e indiferenciados, sobre los que puede cómodamente dominar el despotismo (Morales, 1974).

El individualismo racionalista de la Ilustración tuvo su campo más notorio y negativo con el pensamiento utilitarista, de manera muy general, la critica a los derechos humanos, a la religión natural y la propuesta de una nueva ética fundada en el deleite de la vida y el objetivo de lograr la mayor felicidad a través de aumentar la búsqueda del placer y disminuir el dolor de Jeremy Bentham (1748-1832) y las ideas del gobierno natural y en transición, así como de libertad, progreso y utilidad de John Stuart Mill (1806-1873) pueden ser consideradas las bases del argumento del conservador. El conservadurismo moderno es hijo de la Revolución Industrial y de la Revolución Francesa, lo que ambos movimientos atacaron fue defendido por los conservadores (Nisbet, 1995).

El complejo movimiento intelectual conocido como Ilustración no es una estricta representación del empirismo, para el entendimiento de éste hay que agregar los elementos que provienen del racionalismo idealista y del cartesianismo. Empero, el pensamiento ilustrado lo podemos incluir en la corriente empirista por dos argumentos: 1) porque el empirismo depende, en buena medida, del racionalismo continental, supone la influencia de éste y no se opone al mismo y 2) la Ilustración se preocupó más del conocimiento que de la metafísica, en la medida y posibilidades de su filosofía, sigue el camino de los empiristas y extremándolos se acerca al sensualismo absoluto, los sentidos son la única fuente del conocimiento. La Ilustración es el periodo de difusión de las ideas, representa el término de la deliberación metafísica y el arribo a la socialización y trivialización de las ideas del periodo anterior: igualdad, libertad, fraternidad, religión natural, positivismo jurídico, supremacía del Estado, entre otras. El conocimiento basado en la experiencia y percepción heredado del empirismo hacia el positivismo, es una pieza clave de la argumentación científica. El positivismo rechaza todo tipo de doctrina y de filosofía política por carecer de un carácter científico y democrático, el conocimiento positivista se construye tomando en consideración el análisis de los hechos, verificados a través de la experiencia. El movimiento radical que estimulo la transformación de las ideas lo identificamos como la Revolución Francesa (Russell, 2009).

La modernidad liberal inglesa se hizo presente con Robert Filmer (1588-1653), Thomas Hobbes (1588-1679), John Locke (1632- 1704), Thomas Paine (1737-1809), Jeremy Bentham (1748-1832) y John Stuart Mill (1806-1873).

En Francia los ejemplos de las ideas del liberalismo se representaron con René Descartes, (1596-1650), Charles Louis de Secondat y Barón de Montesquieu (1689-1755), François Marie Arouet (1694-1778), más conocido como Voltaire, Denis Diderot (17131784), Jean-Baptiste Say (1767-1832), Charles-Jean Baptiste Bonnin (1772-1846), Emilio Durkheim (1858-1917), Henri-Benjamin Constant de Rebecque (1767-1830).

En Escocia el liberalismo estuvo representado por David Hume (1711-1776), Adam Smith Douglas Junior (1723-1790) y Adam Ferguson (1723-1816). 
En el liberalismo alemán destaca Juan Enrique Amadeo Von Justi (1717- 1771) y Max Weber (1864-1920) aunque no es considerado por algunos como un pensador liberal, ya que uno de sus principales aportes fue haber racionalizado la explicación de la acción social, los tipos ideales, la dominación y al Estado, empero es un muy buen ejemplo de lo que es ser un liberal.

La herencia europea de los intelectuales liberales, fue matizada en Estados Unidos por James Madison (1751-1836), Thomas Paine (1737-1809), Thomas Jefferson (1743-1826), Thomas Woodrow Wilson (1856-1924), Frederick Winslow Taylor (1856-1915) y por Frank Johnson Goodnow (1859-1939).

\section{Tabla 1: La modernidad liberal progresista}

\begin{tabular}{l} 
Individualismo: independencia y autosuficiencia en la búsqueda de la satisfacción de los \\
objetivos \\
\hline Igualdad: abolición de privilegios \\
\hline Libertad moral: ampliación y ejercicio de más libertades \\
Técnicas racionalistas de organización del poder: ampliación del sufragio universal a la \\
naciente burguesía agrícola y la constitución de una República \\
\hline Libertad de conciencia: actitud laica en el pensamiento y acción del hombre \\
\hline $\begin{array}{l}\text { Soberanía popular: supremacía de la autoridad civil, secularización de la sociedad y } \\
\text { separación de la Iglesia y el Estado }\end{array}$ \\
\hline Democracia: abolición de privilegios \\
\hline Sufragio universal: extensión del voto a toda la población \\
\hline $\begin{array}{l}\text { Estado centralizado: unidad de la nación como resultado del interés general o del interés } \\
\text { común }\end{array}$ \\
\hline Universalización: igualdad de la aplicación y utilidad de los conceptos (isomorfismo)
\end{tabular}

Fuente: Elaboración propia con información de Strauss (2007), Santirso (2014), Burke (2010) y Nisbet (1995).

\section{Los orígenes del conservadurismo}

Los orígenes del conservadurismo están en las denostaciones a la Ilustración y en la concepción organicista de la sociedad -de manera genérica se apela a la utilidad propia de la sociedad y el Estado y no a los derechos humanos-, en el movimiento romancista y en la tradición moderna de nación. El romanticismo floreció en los países que fueron claramente afectados por el desarrollo político, económico y social de la Revolución Francesa, el anheló de cambió de la perspectiva individualista predominante en el pensamiento ilustrado, las modificaciones estructurales que represento la propia Revolución y la cosmovisión liberal-burguesa caracterizada por la tendencia expansionista a través de la creación de un mercado único de Napoleón Bonaparte, confluyen en el surgimiento del romanticismo político alemán. En el contexto histórico europeo, el nacimiento del pensamiento liberal fue acompañado de un movimiento de oposición contra el excesivo racionalismo de la vida burguesa, su crítica hacia la sociedad 
con matriz individualista y su proyecto de modernidad racionalizada, el movimiento del romanticismo aporto una cosmovisión de recambio, diferente, de retorno al pasado ideal, de recuperación de las condiciones propias de la historia de las sociedades. El romanticismo político mantiene una proximidad con el proyecto conservador o moderado de la modernidad. El romántico, sin embargo, entiende que en el interior del hombre actúan distintas fuerzas, y que la esencia de lo humano rebasa la esfera de lo inconsciente y de lo racional. El romántico, además de su rebeldía contra el orden del mundo heredado, se opone a la separación entre razón y sentimiento, entre lo real y lo irreal. La belleza, en consecuencia, ha de proporcionar un estado de placer sereno, fruto del orden y la proporción, como ocurre con el arte griego (Croce, 1996).

La concepción organicista de la sociedad civil que tiene el pensamiento conservador, no está formada por contratos libres e individuales, por acuerdo entre las partes, por el contario, está formada por organismos que existen de manera previa a la voluntad individual, por instituciones que han motivado un valor, a los integrantes de la comunidad, la garantía de la presencia de estos órganos permite la existencia de la libertad de los individuos (Nisbet, 1995).

El romanticismo se opuso a la racionalización de la ilustración, al despotismo ilustrado, a la primera revolución industrial inglesa (1760-1860), a la igualdad y libertad natural. Algunos autores alemanes e ingleses del movimiento romántico son: Gotthold Ephraim Lessing (1729-1781), Johann Gottfried von Herder (1744-1803), Johann Christoph Friedrich Schiller (1759-1805), Johann Wolfgang von Goethe (1749-1832), William Wordsworth (1770-1850) y George Gordon Byron (1788-1824), estos se caracterizan por reflexionar en la relación que mantiene la religión natural y la religión revelada (Forster, 2001).

Las ideas del romanticismo alemán ofrecían una concepción orgánica de la vida social, contraria al individualismo atomístico, funde cierta intuición mística del Estado como un Dios terrenal con las fuerzas espirituales de todos los individuos dirigiéndolas hacia una finalidad superior nacional y moral. El romanticismo alemán encontró buen recibimiento entre las clases tradicionales por su simpatía con lo indígena. El romanticismo se constituyó como la comunión viviente de espíritus. Los conservadores consideraban que había que ampliar su base, edificándola no sobre la torre del privilegio, sino sobre la plataforma de los sentimientos y de los intereses del pueblo (Guiomar, 2001).

En Inglaterra el viejo programa Tory había creado un gobierno oligárquico a semejanza del gobierno liberal, el primero asociado con la riqueza y el privilegio tradicional y el segundo asociando a la riqueza con otro tipo de privilegios. El primero fortalece al Estado y el segundo lo debilita. Para los conservadores los liberales pretenden debilitar al Estado porque querían dejar el juego libre a la concurrencia de las fuerzas más endurecidas con perjuicio de las más frágiles y con plena facultad de explotación de las masas indefensas, que constituyen la materia y no son protagonistas de la concurrencia, suprimiendo todo poder superior a los individuos, capaz de ejercer una función moderadora y equitativa. A la doctrina de la concurrencia se opone la de la solidaridad, de la colaboración, de la asistencia mutua, cuya expresión más elevada y comprensiva es el Estado. Robert Owen (1771-1858) dará el ejemplo de esta concepción más humana de las relaciones entre patrones y obreros, elevo a fórmulas de carácter 
universal el asociacionismo entre los miembros de la comunidad. Owen solicito en vano a sus demás patronos un espíritu humanitario para con los obreros, su iniciativa resulto aislada, la opción podía y debía producirse desde abajo, a través de la espontánea coalición de los obreros. El resultado fue el cooperativismo y el tradeunionismo después de la llegada del liberalismo. Sobre este punto los conservadores observaron cierto peligro, la inestabilidad e inseguridad de la vida política por la absoluta separación de las dos clases obligadas a vivir juntas. En Inglaterra los conservadores realizaron programas populares y democráticos que pusieran freno a la supervivencia del viejo régimen aristocrático, en Alemania se acentúo la unidad nacional solidaria, en Francia se apeló a buscar la mejor Constitución que sirviera al pueblo (Giocanti, 2010).

En Francia Charles Perrault (1628-1703), Antoine Houdar de La Motte (16721731), Bernard Le Bovier de Fontenelle (1657-1757), Denis Diderot (1713-1784), Jean-Jacques Rousseau (1712-1778), Jacques-Henri Bernardin de Saint-Pierre (17371814), François-René, vizconde de Chateaubriand (1768-1848) son considerados escritores románticos, se caracterizaban por registrar las costumbres de la época, la inconformidad de las mayorías con su situación y la esperanzas de la gente por un período histórico, donde todos serían felices. El aporte de la obra literaria de Jean-Jacques Rousseau (1712-1778) es un caso particular, en Julia, o la nueva Eloísa (1761), se encuentra una profunda exaltación y admiración de la naturaleza y de los paisajes del momento; en Discurso sobre el origen de la desigualdad entre los hombres (1775) sugiere que la civilización a corrompido al hombre; en El contrato social: o los principios del derecho político (1762) plantea la libertad e igualdad de los hombres para constituir un Estado civil a través de un contrato social, y en Emilio, o de la educación (1762) argumenta el carácter sentimental, el sentido pedagógico y el ideal de sencillez con el que se tiene que educar a los hombres. Los planteamientos russonianos son particulares ya que denuncian el carácter ilegitimo de casi todos los tipos de gobierno y el encadenamiento que la sociedad civil hace al hombre a través de la ley. Rousseau descarta el mito de la Ilustración, al sugerir que el progreso de las ciencias y las artes no impacta de forma directa en el progreso de la sociedad civil y la felicidad humana. La Ilustración produce corrupción moral ya que necesita del ocio, el lujo y fomenta los vicios. La polis griega representa uno de los mejores modelos de sociedad civil, por su libertad y autonomía, por fundarse en la buena ciudadanía, en los valores, en la moderación y abnegación (Rousseau, 2006).

La simpatía de Rousseau por la república lo hace pensar en la libertad e igualdad de los hombres, el camino a una sociedad moral, a una república no es la Ilustración sino una rígida educación moral. El sentido común generalizado de conservación lleva al hombre a proporcionar vida, de manera convencional, a la sociedad civil y al Estado. Por otro lado, la justicia es privada de la sociedad política, en está los privilegios, el honor, la riqueza y la nobleza son protegidos por las leyes, normas que no necesariamente son obligatorias para los desprotegidos, la moral y las condiciones de igualdad en la propiedad son propias de la naturaleza humana, es decir, la moral es la parte viva que regula el tipo de contrato social.

El único sujeto que da vida al poder político es el pueblo, el poder soberano reside en el pueblo, todos los miembros asociados que integran un cuerpo soberano otorgan vida a la república. Como se puede percibir, el pensamiento de Juan Jacobo Rous- 
seau se encuentra en una constante tención, entre la revolución, la democracia y el conservadurismo. Rousseau se inclinó por la democracia en una época en la que la democracia no existía, en las condiciones históricas de Rousseau lo más cercano a la democracia eran las ideas de libertad, igualdad y propiedad, favorables al liberalismo progresista y a las revoluciones burguesas, en un inicio podría ubicarse a Rousseau como un pensador liberal progresista, no obstante, su pensamiento presenta una mayor cercanía con los principios conservadores (Touchard, 2006). Rousseau retoma el orden del cosmos planteado por Isaac Newton (1642-1727), en el los planetas giran uniformes en torno al sol en órbitas preestablecidas, para sugerir de manera imaginativa la condición del buen gobierno, el freno de las pasiones desbocadas sería la educación (Russell, 2009).

Los movimientos nacionalistas suponen que el nacionalismo es un sentimiento, que toda entidad cultural y política debe constituirse en un Estado independiente, sostienen que la perfección es pequeña y delicada, no provoca sobresalto, produce placer y asegura la conservación, los grupos humanos con vínculos comunes (lengua, raza, lazos históricos comunes) pueden conformar un todo homogéneo, una nación -Louis Gabriel, vizconde de Bonald (1754-1840), Johann Gottlieb Fichte (1762-1814), Karl Ludwig von Haller (1768-1854), Karl Wilhelm Friedrich von Schlegel (1772-1829), Samuel Taylor Coleridge (1772-1834), Arthur Schopenhauer (1788-1860), Joseph Ernest Renan (1823-1892) y Charles Maurras (1868-1952), pueden ser ejemplo de ello- (Nisbet, 1995).

La revisión del conservadurismo se hace compleja por la dificultad de encontrar y coincidir con una definición única (González, 2013). El conservadurismo es entendido desde una condición psicológica propia del ser humano, una actitud de defensa al statu $q u o$, hasta una corriente ideológica clásica. Existen dos usos comunes del vocablo conservador, como sustantivo, como la existencia de un concepto y como adjetivo, como la cuantificación de posicionamientos prácticos e ideológicos (Bonazzi, 2015). El conservadurismo se ha expresado en un conjunto de conceptos claramente definidos desde el siglo XVIII, es una reflexión sobre la sociedad, el Estado, el gobierno y una serie de componentes culturales indispensables en la teoría política. El origen del conservadurismo como movimiento e ideología política está unido a las corrientes revolucionarias que se desataron en el siglo XVIII en Europa, principalmente en Francia (Pessoa, 2013). Los europeos encontraron en el término «conservador» la terminología filosófica perfecta para denotar la resistencia contra la atmosfera que se vivía con la Revolución Francesa y los ideales de los Clubs Jacobinos. En 1746 Justus Möser (17201794), miembro destacado del romanticismo político alemán, manifiesta su inconformidad al racionalismo, al individualismo y sobrepone la idea que la constitución de un país es producto de su contexto socio histórico y de la maduración de sus instituciones. Empero, el inglés Edmun Burke (1729-1797) es considerado el precursor del conservadurismo.

El conservadurismo sugiere un desafío directo a los valores del pensamiento ilustrado: plena independencia y autosuficiencia; el racionalismo sin prohibiciones sólo puede llevar a la destrucción. El conservadurismo se sostiene en tres valores: 1) autoridad, 2) lealtad y 3) tradición. El término conservador aparece por primera vez en Francia en 1819, el diplomático y político francés François-René, vizconde de Chate- 
aubriand lo utilizó para hacer referencia a todas aquellas ideas que se oponían a las condiciones liberales anteriores y ulteriores a la Revolución Francesa. El conservador se esfuerza en utilizar la razón práctica y la imaginación moral y rechaza a todo pensamiento liberal. Niega a la ideología pero no niega la necesidad de ciertos principios, el individuo es un ideólogo pero la especie humana una sabia, desconfía del intelectual, del ilustrado que quiere reconstruir a la sociedad y a la naturaleza humana con su limitada razón privada, no se imagina que un sistema determinado de conceptos políticos, aplicados uniformemente, pueda traer la justicia, la paz, la libertad y la igualdad de todos los hombres en todas las épocas (Nisbet, 1990).

Para el conservador el pensamiento abstracto es aborrecible, significa forzar a los hombres y a las sociedades a un canon preestablecido de manera independiente carente de toda circunstancia de tiempo y espacio. En el pensamiento conservador los fenómenos económicos, políticos, sociales, culturales y éticos se mezclan con los fenómenos religiosos, está cuestión social refleja una jerarquía de dificultades así como una jerarquía de valores. La naturaleza no es un objeto, un todo mecánico como quería René Descartes (1975), sino un todo orgánico, vivo. El «yo» rechaza formar parte del cosmos como una pieza más de su engranaje, y por el contrario, hace constar su individualidad, su capacidad creadora y transformadora que extrae de sí mismo, de su interior, y plantea una relación con la naturaleza como una comunicación de uno a uno o de uno al todo, que a la vez desencadena su aspiración al infinito (Gottlieb, 2002).

La sustancia filosófica del conservadurismo oscila entre el Estado, el individuo, las estructuras de grupos y las asociaciones que se sitúan en un lugar intermedio entre dos entidades opuestas, el Estado y el individuo (Schelling, 2014). Las experiencias son fundamentales para el conservadurismo, la historia está compuesta por un cúmulo de experiencias, la historia de las experiencias se sobrepone al pensamiento abstracto y deductivo, la confianza se funda en la historia de las experiencias (Schlegel, 2007). La legitimidad es el resultado de la historia y de las tradiciones que van más allá de los recursos de cualquier generación particular o de sólo un pacto social. El conservador tiene sus raíces en el pasado y busca lo permanente, confía en las costumbres, los hábitos y las instituciones tradicionales (Schlegel, 2009). El conservador no se opone a las grandes mejoras, aunque si niega la existencia de algún tipo de fuerza como un progreso místico actuando en el mundo. Cuando una sociedad progresa en una cosa regularmente decae en otra, una sociedad saludable tiene que cuidar la permanencia y el progreso. El cambio es esencial para la conservación (Forster, 2001). El diseño institucional para el conservadurismo tiene una fuerte carga de las condicionantes sociales y del valor histórico de las estructuras de grupos.

La esencia moral del conservadurismo gira entre la prudencia a los cambios que puedan representar una pérdida irreparable y la nostalgia de la pérdida de un orden previo. El conservadurismo no es enemigo del progreso y de la libertad, afirma que sólo mantener el orden que el progreso amenaza garantiza la libertad. El ethos del conservadurismo está en la tradición, esencialmente en la tradición medieval, en la defensa a los valores de la comunidad, el parentesco, la jerarquía, la autoridad y la religión. 


\section{La modernidad de los liberales moderados o conservadores}

El movimiento intelectual conocido como conservadurismo pretendió recuperar el orden social y detener la decadencia de la humanidad que acarrearía la democracia. El asidero de la razón para el conservadurismo está en el elemento explicativo de los fenómenos naturales y sociales, la providencia divina es el eje primario que explica al evolucionismo, progreso, reformismo y dirigismo. El pensamiento conservador entiende a la modernidad, como el cúmulo de las circunstancias humanas que son extraordinariamente variables, todo análisis de estás se emprende tomando en cuenta las particulares circunstancias de tiempo y lugar, el oportunismo ilustrado o la prudencia son las bases del conocimiento (Russell, 2009). Para el conservador, el conocimiento racional y prudente es el que se obtiene de la conciliación de la sabiduría de nuestros antepasados y los cambios vertiginosos del presente (véase Tabla 2). El legado del conocimiento racional, empírico y positivista no logro presentarse plenamente escéptico, legitimo el conocimiento científico, no obstante, no preciso de manera positiva en qué consiste el conocimiento científico. En una manifestación escéptica se ocultó un dogmatismo (Strauss, 2007).

La tradición heredada por el empirismo se puede observar en la propuesta de Henri de Saint-Simon (1760-1825) de crear un nuevo y autentico cristianismo que fuera la base ideológica y moral de un socialismo aristocrático que dirigiera a la naciente sociedad industrial y disminuyera la pobreza, así como en la ley de los tres estadios de Augusto Comte (1798-1857) y su idea de conocimiento positivo fundados en las experiencias del contexto de la Revolución Francesa.

El conservadurismo en Inglaterra se hizo presente con las voces de Richard Hooker (1554-1600), Edmund Burke (1729-1797), Samuel Taylor Coleridge (1772-1834), Robert Southey (1774-1843) y Benjamín Disraeli (1804-1881). El más destacado protagonista del conservadurismo fue Edmun Burke (2010), escritor, filósofo y político, es el iniciador del liberalismo conservador británico y defensor de los viejos liberales (old whigs). Para Burke (2009) todas las instituciones políticas, sociales y religiosas son producto del conocimiento y experiencia atesorados a lo largo de los siglos, manda una señal conservadora al manifestar que la Revolución Francesa no es una búsqueda de libertad frente al poder opresivo, la considera como la búsqueda del poder absoluto, como la obra de un grupo de intelectuales que no tenía ningún interés o aprecio por la sociedad. La individualización de la sociedad que acompaño a la Revolución Francesa asisto al florecimiento de tipos de propiedad territorial, más fluida, monetaria y móvil, la Revolución exalto a una nueva clase al poder económico. En 1791 se abolieron todas las corporaciones francesas, sólo existe el interés particular de cada individuo, en 1792 el matrimonio se declara contrato civil y los vínculos de propiedad fueron desechados. La propiedad y herencia se convirtió en una tarea de la acción legislativa. Para Burke la individualización y racionalización de los recursos, por parte del gobierno, acompañaron a la Revolución. Manifestó su desconfianza hacia el comercio y hacia la identificación impersonal de los seres humanos reduciendo su condición a simples propietarios, en cierta medida por los efectos de la industria y el comercio sobre el vínculo histórico y social.

El conservadurismo en Francia se ejemplifico en las ideas de Jakob Böhme (15751624), Blais Pascal (1623-1662), Louis Claude de Saint-Martin (1743-1803), Joseph-Marie, 
conde de Maistre (1753-1821), Luis de Bonald (1754-1840), François-René de Chateaubriand (1768-1848), Auguste Comte (1798-1857) y Alexis de Tocqueville (1805-1859).

El pensamiento conservador también se manifestó en el movimiento nacionalista francés a través de Joseph Ernest Renan (1823-1892) y por Charles Maurras (18681952). Finalmente en el movimiento denominado naturalista encontramos a Hippolyte Adolphe Taine (1828-1893).

Una respuesta en Alemania fue el Idealismo, representado por Albrecht von Haller (1708-1777), Immanuel Kant (1724-1804), Johann Gottlieb Fichte (1762-1814), Georg Wilhelm Friedrich Hegel (1770-1831), Karl Wilhelm Friedrich von Schlegel (1772-1829), Friedrich Karl von Savigny (1779-1861) y por Carlos Marx (1818-1883).

En el siglo XIX se presentaron unas corrientes filosóficas de revaloración humana, estás se enfrentaron a la situación, que según el positivismo encaro sin comprender: la razón se ha tornado un inconveniente desde su origen. Los argumentos de Arthur Schopenhauer (1788-1860), Wilhelm Richard Wagner (1813-1883), Søren Aabye Kierkegaard (1813-1855) y Friedrich Wilhelm Nietzsche (1844-1900) son un ejemplo.

En España las ideologías conservadoras se presentaron con Juan Donoso Cortés (1809-1853), Miguel de Unamuno (1864-1936), José Ortega y Gasset (1883-1955) y recientemente con María Zambrano Alarcón (1904-1991).

En Portugal la reflexión de inconformidad y desasosiego por la falta de nacionalización de los conceptos que estaba produciendo el avasallador proyecto liberal progresista fue asumida por Fernando Antonio Nogueira Pessoa (1888-1935), Fernando Pessoa es considerado neopagano y conservador revolucionario, visionario absolutista, místico político y poeta (González, 2013).

Estados Unidos los principios conservadores fueron matizados, entre otros, por John Adams (1735-1826), Alexander Hamilton (1755-1804) y John Randolph (17731833) (Hamilton, Madison y Jay, 2001).

\section{Tabla 2: La modernidad de los liberales moderados o conservadores}

\begin{tabular}{l} 
Organicismo: la comunidad y la sociedad son un todo orgánico, el individuo sólo desempeña \\
diversos papeles \\
\hline Autoridad moral: representación tradicional de la aristocracia \\
\hline Jerarquía: simbolizada por el alto clero y las altas jerarquías del ejército \\
\hline Lo sagrado: identidad del poder de la Iglesia con el poder del Estado \\
\hline Libertad tradicional: limitación de libertades para el pueblo \\
\hline Instituciones tradicionales: familia iglesia, comunidad local y privilegios sociales \\
\hline Desigualdad natural: consolidación de los privilegios heredados \\
\hline Ampliación paulatina del derecho al voto \\
\hline $\begin{array}{l}\text { Descentralización: adopción de formas federales de organización de los estados a través de } \\
\text { sociedades o entidades intermedias }\end{array}$ \\
\hline $\begin{array}{l}\text { Particularismo: matizar la aplicación y utilidad de los conceptos en función de la lógica de } \\
\text { los hechos }\end{array}$
\end{tabular}

Fuente: Elaboración propia con información de Strauss (2007), Santirso (2014), Burke (2010) y Nisbet (1995). 
Organicismo: la comunidad y la sociedad son un todo orgánico, el individuo sólo desempeña diversos papeles Autoridad moral: representación tradicional de la aristocracia Jerarquía: simbolizada por el alto clero y las altas jerarquías del ejército Lo sagrado: identidad del poder de la Iglesia con el poder del Estado Libertad tradicional: limitación de libertades para el pueblo Instituciones tradicionales: familia iglesia, comunidad local y privilegios sociales Desigualdad natural: consolidación de los privilegios heredados Ampliación paulatina del derecho al voto Descentralización: adopción de formas federales de organización de los estados a través de sociedades o entidades intermedias Particularismo: matizar la aplicación y utilidad de los conceptos en función de la lógica de los hechos. Fuente: Elaboración propia con información de Strauss (2007), Santirso (2014), Burke (2010) y Nisbet (1995).

\section{La administración pública en las concepciones de la modernidad}

La relación entre la teoría y la práctica de la administración pública se ha establecido con la ponderación de los fundamentos concretos que afectan su realidad. En consecuencia, la construcción del conocimiento administrativo mantiene u omite el carácter histórico-social de la acción gubernamental y particularmente, la relación existente entre la forma de producción de los individuos y sus conceptos que explican el tipo de sociedad (Stuart, 2001). El estudio de la administración pública tiene que partir del análisis concreto de las tendencias de evolución de la sociedad, la exclusión de estos aspectos ha ocasionado que la disciplina, en su vertiente positivista y en buena medida norteamericana, no haya sobrepasado las meras elaboraciones de modelos empíricos y formales que poco aportan a la comprensión real del objeto de estudio de la administración pública, más aun cuando la idea de modernidad liberal progresista no ha permeado todas las capas científicas, sociales, políticas, económicas y culturales de la nación (García de Enterría, 1972).

Para la modernidad liberal progresista la Ilustración se caracterizó por el descubrimiento de la razón matemática -herencia que tiene sus orígenes en el racionalismo aristotélico-- En los inicios del Estado moderno se comienza a hablar de la razón, el Estado actúa como un ente pensante, el Estado personifica a la razón, a la razón de Estado. En el Renacimiento el Estado personifica una fuerte unidad política ya que una razón hace mejor las cosas que varias razones. Nicolás Maquiavelo (1469-1527) funda la razón de Estado en el monopolio que el Príncipe debe de tener de: la diplomacia, milicia, administración de la justicia y la hacienda.

Las denominadas ciencias camerales y la ciencia de la policía, propias de los siglos XVI y XVIII, fueron grandes progresos científicos y políticos en el Estado absolutista ya que desterraron formas estamentales de relación y se convierten en bases fundacionales de formas institucionales de organización del Estado. Las relaciones hereditarias o estamentales darán paso a las relaciones pactadas, a una relación monarca-súbdito justificada en el progreso mutuo. La racionalidad del poder y de las prácticas administrativas, conciernen ideológica y políticamente al Estado absolutista, único responsable de satisfacer las necesidades propias de la existencia humana y de la felicidad de los individuos. El protagonista de la historia secular, separada de todo rasgo metafísi- 
co, es el individuo. La restauración borbónica en 1814 en Francia, después del Imperio Napoleónico, no represento un retorno al régimen anterior al iniciar la Revolución Francesa en 1789, los franceses conservaron todos los logros civiles de la Revolución asentados en el código napoleónico, como la centralización administrativa, presentada con diferentes matices políticos en los departamentos, la educación, el comercio, la industria, la hacienda pública y las finanzas. La propiedad individual y antifeudal continuaba formando la base de la sociedad económica. El régimen concordatario de 1801 entre el Papa Pío VII y Napoleón I de Francia fue conservado, en ese momento la clase gobernante era la burguesía, fundamentalmente terrateniente, pero con nuevas fuentes de riqueza como la manufactura y el comercio (Guerrero, 1996).

Los orígenes de las ciencias de la administración se remontan a inicios del siglo XVIII en el Estado de Prusia, la Guerra de los Treinta Años (1618-1648) y el fin de esta con la Paz de Westfalia (15 de mayo y 24 de octubre de 1648) obligaron al Reino de Prusia a recuperar su grandeza, durante el reinado de Federico Guillermo I (16881740) tuvieron lugar las primeras cátedras de enseñanza sistematizada de los quehaceres administrativos a los servidores del Estado. En 1723 creó el Directorio General Supremo de Finanzas, de la guerra y de los territorios y en 1728 crea el Departamento de Exteriores (Guerrero, 2004).

La administración pública del Estado absolutista aún conserva una estrecha relación con la Ciencia de la Policía, con la actividad inquisitoria del Estado. El siglo XVIII y el pensamiento alemán son el escenario del florecimiento de las Ciencias Camerales, los primeros elementos los encontramos en los estamentos independientes y en la figura de los oficiales en 1576 con Juan Bodino (1529-1596) en Francia. En Alemania Juan Enrique Amadeo von Justi -considerado como el mayor cameralistaprotagonizo la independencia de la Ciencia de la Policía, distinguió enfáticamente la economía, la cameralistica y la policía. Justi impartió una asignatura relativa a la cancillería, dirigida a los servicios públicos del interior, del exterior y a los altos mandos militares en 1746 en la Academia Teresiana en Viena, creada por la reina María Teresa (1740-1780). En 1765 es nombrado por Federico II (1712-1786) -Federico el Grande, tercer rey de Prusia - Superintendente de Marina.

En 1808 Charles-Jean Bonnin publicó en Francia sus Principios de administración pública, en estos Bonnin (2010) propone la necesidad de ordenar los trabajos del gobierno, los conocimientos y la enseñanza propia de éstos, a través de un Código Administrativo y de Orden Judicial -en buena medida inspirado en el Código Napoleónico-. La libertad, la igualdad, el sistema representativo, la división de funciones y los pensamientos liberales, son las fuentes de donde emanaran los principios de administración pública: 1) la administración nació con la asociación o comunidad, 2) la conservación de está es el principio de la administración, 3) la administración es el gobierno de la comunidad y 4) la acción social es su carácter, y su atribución la ejecución de las leyes de interés general. Para Bonnin (2010: 170) «administrar es la regla general; juzgar es la regla particular». La administración pública es «la que tiene la gestión de los asuntos comunes respecto del ciudadano como miembro del Estado» (Bonnin, 2010: 171). En general, la administración pública, es la fuerza que ordena, corrige y mejora cuanto existe, conduce al bien a los seres organizados como a las cosas. Como ciencia determina la naturaleza de los objetos que comprende con su doctrina propia. 
Como entidad social tiene sus elementos legislativos designados por la naturaleza de las cosas que arregla, es el gobierno de la sociedad. Se fundada para cuidar a los pueblos, a las personas y a los bienes. La utilidad de la administración es su aplicación directa, su acción ejecutiva. Como ley o voluntad es pasiva, como ejecución determina la aplicación de la ley (Justi, 1996).

En la concepción liberal progresista el estudio de la administración pública difícilmente puede disociarse de la evolución y desarrollo del Estado, y no se diga de su aparato administrativo o burocrático que es la propia administración: el Estado no puede comprenderse de espaldas a la administración, puesto que ésta es la que le da contenido aquél, siendo así que la administración es el cuerpo del Estado y lo que un Estado hace realmente es a través de su administración (Nieto, 1996). Una evolución que, como bien dice Ferrel Heady (1996), podría dividirse en dos etapas: la primera en la que el estudio no es propiamente sistematizado y que va desde la Arthasastra de Kautilya en la India, la Política de Aristóteles, pasando por El Príncipe de Maquiavelo, El Contrato Social de Rousseau, el Leviatan de Thomas Hobbes hasta una segunda etapa en la que se observa una sistematización en el estudio a partir de las Ciencias Camerales en Alemania, las Ciencias de la Policía en Francia, el estudio de la administración pública con una orientación positivista, las relaciones intergubernamentales y las políticas públicas en los Estados Unidos, la nueva gestión pública y lo que se conoce hoy en día como gobernance, gobernanza o Estado red; todas ellas mantienen como pieza clave la separación de la política y la administración (González, 2015).

Para el liberal progresista cualquier teoría y técnica administrativa es correcta, independientemente del contexto de que se trate, el problema de la sociedad y del Estado es originado por el ejercicio económico o del sistema industrial, para el liberal la única distinción natural es entre el capitalismo y el socialismo. La administración pública para el pensamiento liberal progresista es el punto medio de la relación dual que procede de la dicotomía individuo-Estado, es la soberanía en constante tensión con las autoridades e intereses tradicionales.

Para la modernidad conservadora, los valores tradicionales aparecen manifiestos en una estructura conceptual y en sus supuestos fundamentales -difícilmente compatibles con el universo liberal progresista-. La idea de administración pública para la modernidad conservadora se asume a partir de una desconfianza frente al poder del Estado; adhesión de la libertad sobre la igualdad; simpatía por las instituciones, las costumbres y las jerarquías; desconfianza ante la idea de progreso y un privilegio por el elitismo (Burke, 2010). Los planes y remedios particulares son temas que deben ser revisados y discutidos con frecuencia, no preestablecidos por un pensamiento abstracto, lo común del pensamiento conservador es la percepción sobre la naturaleza humana, los fines de la sociedad y los métodos más adecuados para satisfacer el bien común.

El conocimiento en el conservadurismo tiene un origen práctico, la base central son las tradiciones, la relación religión e iglesia y la comunidad-familia. Lo relevante de la relación entre la tradición y el saber administrativo no está en privilegiar a la una sobre el otro, sino en resaltar la naturaleza diferente que cada tipo de conocimiento supone y la forma como se ha conformado históricamente un campo del saber con una profesión con alto sentido público. Durante años las sociedades construyeron conocimientos confiables a partir del saber práctico, pero es en nuestra época cuando las valoraciones 
excesivas sobre el conocimiento científico han desvalorado otras formas del conocimiento como el conocimiento común, popular y práctico. En estas condiciones enfrentamos un supuesto saber científico y el uso de técnicas imparciales con prácticas altamente fundadas en un conservadurismo (Kirk, 2003).

Para ejemplificar el concepto de práctica en la administración pública, es necesario remitirnos a las condiciones de las sociedades primitivas, y en general preestatales, en las que el hombre debe resolver su problema de supervivencia. Dado que el hombre ha debido enfrentarse al mundo natural para aprovechar los recursos que garanticen su vida, han sido necesarias históricamente una serie de prácticas que podrían denominarse como prácticas administrativas y que están en el orden de la gestión y administración de recursos, que pueden ser: alimentos, ganado, herramientas, capacidad de trabajo humano, el fuego, el conocimiento de los cambios climáticos para el cultivo de las tierras o para el uso de las armas, por mencionar algunos. Las sociedades llegaron a conclusiones sobre cómo debía organizarse para producir lo que necesitaba y paulatinamente integró un argumento empírico que se transmitió de generación en generación bajo las circunstancias de cada pueblo. Esta teoría empírica-que se refiere a la recuperación de las condiciones materiales de la existencia y la capacidad del hombre para incorporarse a las relaciones de producción y transformarlas activamente- fue durante siglos una práctica económica y cultural de la cual se originó posteriormente un saber administrativo (Uvalle, 1993).

Pero existen también actividades más complejas, que trascienden una relación más directa con la naturaleza, y cuyo manejo también hace parte de los propósitos de bienestar que el ser humano debe lograr: actividades en el orden de lo social, lo económico y lo político, por ejemplo. En resumen, la práctica administrativa como tal, deviene del hacer directamente, teniendo en cuenta la experiencia que se adquiere a partir de la realización misma de actividades tendientes a obtener un fin determinado -el bienestar general para el liberalismo progresista y el progreso moderado inmerso en un orden social y un poder nacional heredado para los conservadores-a hacer un uso óptimo de los medios con los que se cuenta para cumplir tal fin, y al logro de la supervivencia individual y la de la comunidad. La administración pública para el conservadurismo está compuesta por las estructuras de grupos, asociaciones e instituciones que responden a una tradición histórica, representa el punto medio de una relación triangular entre el Estado y el individuo. La administración pública son organizaciones gremiales y las cooperativas que representan al Estado nacional.

Como se puede interpretar, existe una cercanía de la modernidad liberal o progresista con el modelo racional para la toma de decisiones y de la elaboración de las políticas públicas, se atiende a procesos cognitivos donde cada etapa sigue un orden lógico, se toma en cuenta el cálculo de las alternativas para alcanzar el mejor resultado deseado. Mientras que se presenta una proximidad de la modernidad conservadora con el modelo incrementalista de la toma de decisiones y de la hechura de las políticas, con las tendencias de consecución de un objetivo por medio de una serie de incrementos graduales, o pequeños pasos, las acciones del gobierno están sustentadas en una continuación del gobierno anterior, la experiencia, la práctica y la tradición juegan un papel fundamental en los actos de gobierno. La administración pública en los principios liberales se acercaría a la objetividad e imparcialidad de sus resultados, a observaciones 
medibles y cuantificables como medio de legitimación. Mientras que la administración pública en los principios del conservadurismo, buscaría su legitimación no en los resultados sino en el apego al fundamento u origen del proceso que explica su actuar, en la tradición probada de los procesos (González, 1987).

Durante los siglos XVIII y XIX es posible observar una afinidad de la teoría de la administración pública, con rasgos liberales, en los países de Europa, a inicios del siglo $\mathrm{XX}$ las particularidades nacionales se fueron acentuando formando un universo científico multinacional. En los Estados Unidos la tendencia continua siendo universal, la administración pública pensada como teoría de la organización para la administración pública, como ciencia de policy o governance conviven en un mundo conceptual relacionado por analogías, antónimos, sinónimos y enfoques disciplinarios propios de un sistema estable, comunicado y altamente diferenciado.

\section{Conclusiones}

La dificultad práctica para distinguir al liberalismo del conservadurismo, se atenúa cuando consideramos el hecho que tanto el liberalismo como el conservadurismo presentan a la democracia liberal como fundamento común, ambas difieren del comunismo en fines y medios para lograr una sociedad universal y sin clases. Para los liberales la vía para alcanzar dichos fines es democrática y pacífica, esto excluye a los movimientos internos respaldados por el interés de las mayorías. Los liberales se pretenden acercar, de forma pragmática al Estado universal y homogéneo, a través de una federación de Estados donde la desigualdad económica sea explicada por circunstancias territoriales e históricas. Los conservadores sugieren que el Estado universal y homogéneo se alcanzara a través del respeto a lo particular y heterogéneo, el respeto a la diversidad es fundamental, los conservadores mantienen una desconfianza hacia la universalidad de la razón.

La modernidad liberal o conservadora se observa a través de un conjunto de grupos políticos o acciones de gobierno. El ideal de la Revolución Francesa fue disputado por los constitucionalistas, simpatizantes de una monarquía limitada por una constitución; por los demócratas, sector convencido del sufragio universal y la soberanía popular, con una nula presencia en la Asamblea Nacional; por los jacobinos, grupo político defensor de la Republica, del sufragio universal, de la individualidad de la nación y del Estado centralizado. El intento de huida en 1791 de Luis XVI, fragmento a los jacobinos en dos grupos, uno encabezado por Robespierre y el otro por Antoine Barnave y Jacques Pierre Brissot, el primero propugnaba por la separación de la corona y el establecimiento de una república, el planteaba que una amenaza de guerra con las monarquías extranjeras no era deseable, era preferible establecer un pacto con las élites del Antiguo Régimen y construir una monarquía constitucional. El modelo de democracia de los jacobinos recoge el modelo de democracia planteado por Jean Jacques Rousseau, de sus ideas comunitaristas, de su ideal de ciudadano y del interés común. Finalmente por los girondinos, un grupo político moderado y federalista de la Asamblea Nacional Francesa, estaba integrado con 175 diputados de 749 que componían la Asamblea de la Convención entre 1792 y 1793. Eran intelectuales de la bur- 
guesía y se manifestaban a favor de la resistencia a la revolución, al derecho de voto a quien no pagara impuestos y defendían sus privilegios heredados y ganados sobre los movimientos populares. La revolución la entendían como el cambio, producto de una alianza con la monarquía y la clase noble, con un acotamiento de sus beneficios y autoridad. El Directorio - poder ejecutivo, compuesto por cinco miembros: Jean-François Reubell, Paul Barras, Louis-Marie de La Révellière-Lépeaux, Étienne-François Le Tourneur y Lazare Carnot- formado en 1795 y controlado por los girondinos es fuertemente criticado por los jacobinos, los cuales manifestaban que la Revolución había sido traicionada. A partir del 18 de brumario del siglo XVIII -9 de noviembre de 1799 en el calendario gregoriano- Napoleón Bonaparte, con un golpe de Estado, tratara de recuperar la ley y el orden después de los excesos originados por la Revolución Francesa a través de reformar la administración pública del Estado, recuperando una orientación liberal progresista.

El liberalismo progresista y su consecuente idea de administración pública mantienen una cercanía estacha con el espíritu racionalista francés, a su vez la Ilustración francesa influye en Alemania para la conformación de un movimiento semejante, caracterizado por difusión de los pensamientos del filósofo y matemático alemán Gottfrird Leibniz (1646-1716), la Ilustración alemana presento como características una serie de elementos menos revolucionarios, fundados en una limitada critica de la religión, empero, predomina un espíritu racionalista y científico. El movimiento estético y literario denominado Sturm und Drang (tormenta e ímpetu) y el movimiento religioso con rasgos luteranos conocido como Pietismo que privilegia las experiencias religiosas personales y la lectura de la Biblia serán las principales fuentes del romanticismo Alemán y este a su vez de la crítica reaccionaria contra el espíritu racionalista conocido como idealismo Alemán.

Los liberales progresistas sentirán un aprecio por el mundo clásico de Grecia y Roma y el liberal conservador sentirá una estima por la Edad Media por un acercamiento religioso, por el culto católico y por el estudio y réplica del pasado medieval. Parece que hoy en día las reflexiones sobre la modernidad han quedado ocultas, observamos un conjunto de conceptos y operaciones con cierta carencia de un contexto histórico. Para Juan Donoso Cortés (2006) toda gran cuestión política va envuelta siempre de una gran cuestión teológica.

Los derroteros de los avances científicos en buena medida son producto de la apuesta a la razón humana moderna y sin duda mantienen una fuerte relación con la concepción liberal de modernidad. La naciente burguesía fue la principal impulsora de la democratización social y de la consolidación del método positivista, en la lógica de Copérnico, Kepler, Galileo, Descartes y Comte. La administración pública, como disciplina social, se funda con los principios de la razón moderna representada por René Descartes y se fue nutriendo del empirismo y utilitarismo. En la ideología liberal progresista la administración pública aparece como un medio institucional, objetivo e imparcial para la protección de ciertas formas de propiedad.

Se considera que una fuerte irrupción de la disciplina se dará después de la Segunda Guerra Mundial, cuando el protagonismo de la administración pública así como su crecimiento, nivel de complejidad y sofisticación adquirirán un lugar preponderante. En efecto se puede asegurar que, el crecimiento de las administraciones públicas en las 
últimas décadas en el marco de lo que se conoce como Estados de Bienestar contribuyó de manera notoria a la diversificación de sus funciones y políticas públicas, a una mayor cobertura de servicios públicos, a la gestión de mayores recursos económicos, así como al rediseño de sus estructuras organizacionales. Entre otras cosas, se creó una enorme bolsa de empleo debido al crecimiento del aparato gubernamental-administrativo, y al cada vez mayor control de más información. En contraparte, para hacer frente a tal complejidad, se dio lugar al despliegue de un mejor conocimiento técnico, al desarrollo de herramientas técnico-administrativas para todas las áreas (ya sea a través de su importación del sector privado o elaboración propia), llámese de gestión financiera, de personal, de recursos materiales, entre otros, así como a la formación y capacitación de personal especializado. De igual forma, en el interés de potencializar el campo de la administración pública, precisamente para responder a las nuevas necesidades y condiciones, se tuvo que echar mano de todos los aportes de otras ciencias y disciplinas como economía, ciencias empresariales, derecho, informática, teoría de la organización, estadística, sociología, ingeniería, psicología, entre las más importantes. Con el transcurso del tiempo, las sociedades se han tornado más complejas, de manera que culturalmente están mejor dotadas para superar el saber empírico y práctico sobre el manejo de sus recursos y convertirlo en un saber teórico. Por su sistematicidad y por los procesos históricos de su configuración, estos saberes se han denominado en las sociedades occidentales y principalmente con el advenimiento de la modernidad, como ciencias administrativas.

\section{Bibliografía}

Bonazzi, T. (2015). «Conservadurismo», en Bobbio, N., Matteucci, N y Pasquino, G. Diccionario de política. Siglo XXI-Comisión Bicameral del Sistema de Bibliotecas del Congreso de la Unión, México.

Bonnin, C. J. (2010). Principios de administración pública. Fondo de Cultura Económica, México.

Burke, E. (2009). Vindicación de la sociedad natural. Trota, Madrid.

Burke, E. (2010). Reflexiones sobre la revolución francesa. Alianza, Madrid.

Croce, B. (1996). Historia de Europa en el siglo XIX. Ariel, Madrid.

Descartes, R. (1975). Discurso del método. Aguilar, Buenos Aires.

Donoso Cortes, J. (2006). Ensayo sobre el catolicismo, el liberalismo y el socialismo. Comares, Madrid.

Fernández, A. (2012). ¿Hacia dónde camina occidente? Pasado, presente y futuro de la cultura del siglo XXI. Editorial Bac, Madrid.

Forster, R. (2001). «El conservadurismo revolucionario de Weimar», en Casullo, N., Forster, R y Kaufman, A. Itinerarios de la modernidad. Eudeba, Buenos Aires.

García de Enterría, E. (1972). La administración pública española. Alianza, Madrid.

Giocanti, S. (2010). Charles Maurras. El caos y el orden. Acantilado, Barcelona.

González Cuevas, P. C. (2013). Conservadurismo heterodoxo. Siglo XXI, Madrid.

González Ortiz, B. (1987). La administración pública norteamericana. Origen, crítica y crisis. Fontamara, México. 
González Ulloa, P. A. (2015). «Transformación del Estado. Propuestas metodológicas de análisis para una nueva realidad: La mirada cosmopolita», en Castañeda Sabido, F y Aguilera Hintelholher, R. M. (coords.). La administración pública en el debate contemporáneo de las ciencias sociales. UNAM, México.

González Varela, N. (2013). «Edición crítica», en Pessoa, F. Política y profecía. Escritos politicos 1910-1935. Montesinos, España.

Gottlieb, F. J. (2002). Discurso a la nación alemana. Tecnos, Madrid.

Groethuysen, B. (1943). La formación de la conciencia burguesa en Francia durante el siglo XVIII. Fondo de Cultura Económica, México.

Guerrero, O. (1996). «Estudio introductorio», en Justi, J. E. Von. Ciencia del Estado. IAPEM, México.

Guerrero, O. (2004). «Estudio introductorio», en Bonnin, C. J. Principios de administración pública. Fondo de Cultura Económica, México.

Guiomar, J. Y. (2001). «Romanticismo político», en Philippe, R y Rials, S. (ed). Diccionario Akal de filosofía política. Akal, Madrid.

Hamilton, Alexander, M y James y Jay, J. (2001). El federalista. Fondo de Cultura Económica, México.

Heady, F. (1996). Administración pública. Una perspectiva comparada. Fondo de Cultura Económica, México.

Justi, J. E. von (1996). Ciencia del Estado. IAPEM, México.

Kirk, R. (2003). Un programa para conservadores. El buey mudo, Madrid.

Kofler, L. (1974). Contribución a la historia de la sociedad burguesa. Amorrortu, Buenos Aires.

Laski, H. J. (1974). El liberalismo europeo. Fondo de Cultura Económica, México.

Lassalle, J. Ma . (2010). Liberales. Compromiso cívico con la virtud. Debate, Barcelona.

Lomba Falcón, P. (2014). Márgenes de la modernidad. Libertinismo y filosofía. Escobar y Mayo, Madrid.

Marías, J. (2008). Historia de la filosofía. Alianza, Madrid.

Morales Saro, Ma . C. (1974). Posada Herrera. Del liberalismo progresista al conservadurismo 1814-1868. Llanes, Asturias.

Nieto, A. (1996). Los primeros pasos del Estado constitucional. Ariel, Barcelona.

Nisbet, R. (1990). La formación del pensamiento sociológico. 2 Tomos, Amorrortu. Argentina.

Nisbet, R. (1995). Conservadurismo. Alianza, Madrid.

Pessoa, F. (2013). Política y profecía. Escritos políticos 1910-1935. Montesinos, España.

Rousseau, J. J. (2006). El contrato social o principios de derecho político. Porrúa, México.

Ruggiero, G. de (2005). Historia del liberalismo europeo. Comares, España.

Russell, B. (2009). Historia de la filosofia. RBA, Madrid.

Santirso, M. (2014). El liberalismo. Una herencia disputada. Cátedra, Madrid.

Schelling, F. (2014). La relación del arte con la naturaleza. Globus, España.

Schlegel, F. (2009). Fragmentos. Sobre la incomprensibilidad. Marbot, Barcelona.

Schlegel, F. von (2007). Lucinda. Siglo XXI, México.

Strauss, L. (2007). Liberalismo antiguo y moderno. Katz, Buenos Aires.

Stuart Mill, J. (2001). Consideraciones sobre el gobierno representativo. Alianza, Madrid.

Touchard, J. (2006). Historia de las ideas políticas. Tecnos, Madrid.

Uvalle Berrones, R. (1993). La teoría de la razón de Estado y la administración pública. Plaza y Valdés, México. 